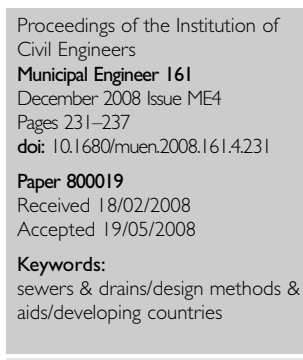

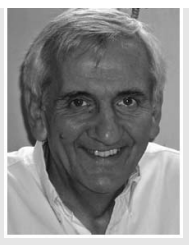

Duncan Mara Professor, University of Leeds, UK

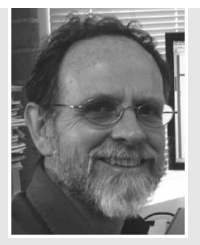

Jeff Broome UK

\title{
Sewerage: a return to basics to benefit the poor
}

\section{Mara PhD, DSc(Eng), CEng, CBiol, FICE, FIBiol, FCIWEM, FRIPH and J. Broome BSc, CEng, MCIWEM}

\begin{abstract}
Around 2.8 billion people, mostly in developing countries, currently lack adequate sanitation. Approximately half live in urban areas, where the most appropriate sanitation solution is commonly simplified sewerage. This paper presents the rigorous hydraulic design basis of simplified sewerage and compares this design approach with that used in the UK for conventional sewerage. It reviews simplified sewerage construction and how this achieves major cost savings and also avoids the problems commonly experienced with manholes.
\end{abstract}

\section{INTRODUCTION}

In 2000 the World Health Organization and Unicef estimated that around $2 \cdot 2$ billion people lacked adequate sanitation; of this number, around half were in rural areas and half in urban areas. ${ }^{1}$ In 2004 this estimate was revised upwards to around $2 \cdot 8$ billion people. ${ }^{2}$ Whereas in rural areas sanitation provision is most likely to be with on-site systems (such as ventilated improved pit (VIP) latrines and pour-flush toilets), in highdensity low-income urban areas there is usually insufficient space for on-site systems for individual households. Often the only viable form of sanitation is low-cost sewerage which is typically 'simplified' sewerage, developed in the northeast of Brazil in the early 1980s where it is also known as 'condominial' sewerage. ${ }^{3-5}$ The basic design concepts of simplified sewerage were incorporated into the 1986 revision of the Brazilian national sewerage design $\operatorname{code}^{6}$ and since then the system has been widely adopted throughout Brazil.

Although simplified sewerage was developed for low-income urban areas (Figure 1), it has also been successfully used in some rural areas, for example in the northeastern Brazilian state of Ceará, ${ }^{7}$ and also in high-income urban areas, principally in Brasília $^{8}$ (Figure 2). Simplified sewerage has also been successfully used in other Latin American countries (notably Bolivia and Peru) and some Asian countries (Pakistan and Sri Lanka).

The principal attraction of simplified sewerage is that its capital costs are approximately half those for conventional sewerage (Table 1; see also Section 4). This means that the monthly charge for the service (typically applied as a percentage surcharge on the monthly water bill) is generally low enough not to cause lowincome households any financial hardship. For example, in January 2008 the monthly charge for simplified sewerage in low- income urban areas in the state of Rio Grande do Norte in northeast Brazil was US\$ 3.50, equivalent to only $1 \cdot 7 \%$ of the minimum wage. ${ }^{9}$

\section{SIMPLIFIED SEWERAGE DESIGN}

\section{I. Development of design equations}

The development of the hydraulic theory of simplified sewerage is important because it demonstrates that its hydraulic design is at least as rigorous as that used for conventional sewerage design, if not more so. The design approach for simplified sewerage used in Brazil is based on the concept of tractive tension, also known as boundary shear stress. ${ }^{10}$ This is the stress experienced by settleable solids within the sewer due to the flow of the wastewater which, if large enough, keeps the solids in suspension and so prevents any solids deposition that may lead to sewer blockage.

There are five other factors that govern the hydraulic design: the minimum peak flow; the minimum and maximum proportional depths of flow (i.e. the depth of wastewater flow $d$ divided by the internal diameter of the sewer $D$ ); the minimum sewer internal diameter and the peak flow factor (i.e. the peak flow divided by the average daily flow). The minimum peak flow is the value used to determine the minimum gradient at the head of the sewer network where the normal peak flow factor has little meaning; the value chosen is intended to represent the discharge from a single WC.

The design values used in Brazil are ${ }^{11,12}$

$\begin{array}{ll}\text { (a) minimum tractive tension, } \tau & 1 \mathrm{~N} / \mathrm{m}^{2} \\ \text { (b) minimum peak flow, } q_{\min } & 1 \cdot 5 \mathrm{l} / \mathrm{s} \\ \text { (c) minimum proportional depth of flow, } d / D & 0 \cdot 2 \\ \text { (d) maximum proportional depth of flow, } d / D & 0 \cdot 8 \\ \text { (e) minimum sewer internal diameter, } D & 100 \mathrm{~mm} \\ \text { (f) peak flow factor (based on measured flows) } & 1 \cdot 8\end{array}$

The tractive tension is derived from the component of the weight of wastewater in a length of sewer that is acting in the direction of flow and is balanced by the tractive tension acting on it. The average tractive tension is given by

\begin{tabular}{c|c}
$\mathrm{I}$ & $\tau \mathrm{g} r \mathrm{i}$
\end{tabular}

where $\rho$ is the density of wastewater $\left(\mathrm{kg} / \mathrm{m}^{3}\right)$, $\mathrm{g}$ is acceleration due to gravity $\left(\mathrm{m} / \mathrm{s}^{2}\right), r$ is the hydraulic radius $(\mathrm{m})$ and $i$ is the sewer gradient $(\mathrm{m} / \mathrm{m})$. The design value for $\tau$ used in Brazil $\left(1 \mathrm{~N} / \mathrm{m}^{2}\right)$ has been found to be adequate in both poor and non-poor housing areas, where 'adequate' means the occurrence of an acceptably low level of sewer blockage. 


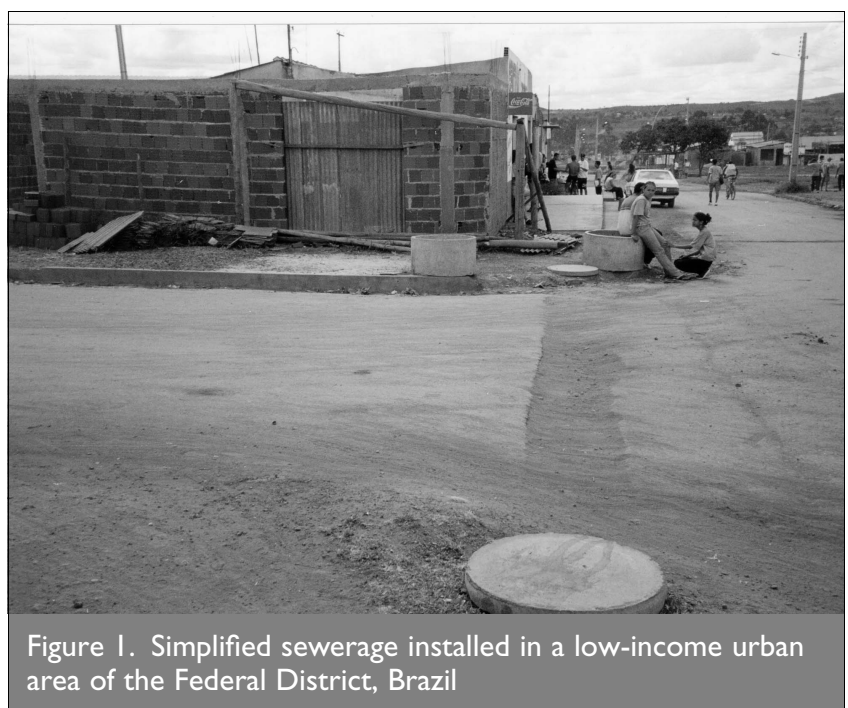

The hydraulic radius $r$ varies with the proportional depth of flow $d / D$ since

$2 \quad r=\frac{D}{4}\left(1-\frac{\sin \theta}{\theta}\right)$

where $\theta$ is the angle subtended at the centre of the sewer by the wastewater surface (radians) and is defined

3

$$
\theta=\cos ^{-1}[1-2(d / D)]
$$

Equation (1) can now be rearranged and written in terms of $D$ instead of $r$

$$
\begin{array}{l|l}
\hline 4 & =\frac{\tau}{\rho \mathrm{g} k_{r} i}
\end{array}
$$

where $k_{r}$ is given by

$$
5 \quad k_{r}=\frac{1}{4}\left(1-\frac{\sin \theta}{\theta}\right)
$$

Manning's equation for the velocity of flow $(v, \mathrm{~m} / \mathrm{s})$ has been found to be sufficiently accurate for designing simplified sewerage (and it has the advantage of being considerably simpler to use than the Colebrook-White equation) ${ }^{12}$$$
6
$$

$$
v=(1 / n) r^{2 / 3} i^{1 / 2}
$$

where $n$ is Manning's dimensionless roughness coefficient (commonly taken as 0.013 and independent of the sewer material

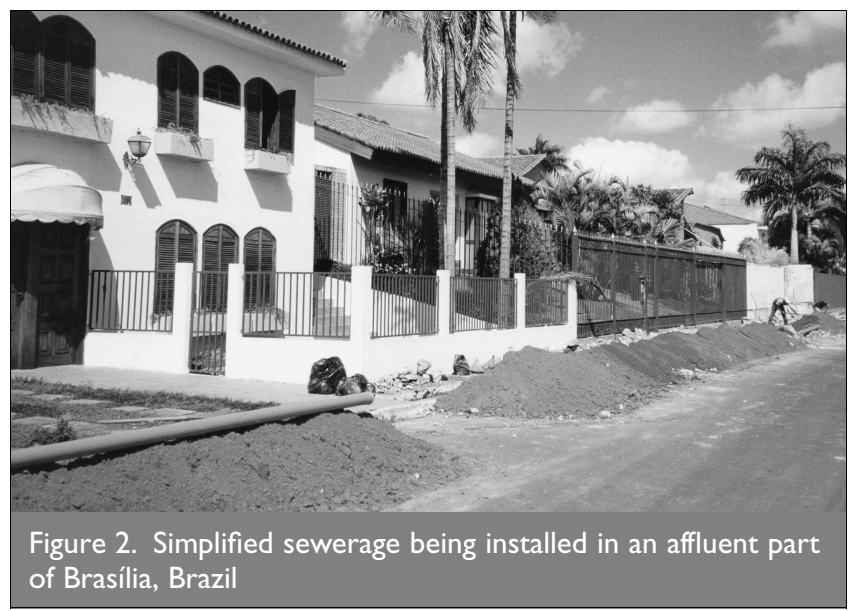

as it depends on the roughness of the bacterial slime layer growing on the sewer wall). Substituting $v=q / a$ in equation (6) and rearranging gives

\section{7}

$$
q=(1 / n) a r^{2 / 3} i^{1 / 2}
$$

where $q$ is the flow in the sewer at a given proportional depth of flow of $d / D\left(\mathrm{~m}^{3} / \mathrm{s}\right)$ and $a$ is the area of flow at this $d / D\left(\mathrm{~m}^{2}\right)$. The area of flow is also given by

$$
8
$$

$$
a=D^{2} \frac{(\theta-\sin \theta)}{8}
$$

Writing $(\theta-\sin \theta) / 8$ as $k_{a}$, then $a$ is

$$
9
$$

$$
a=k_{a} D^{2}
$$

Substituting for $r$ and $a$ from equations (2) and (9), respectively, equation (7) becomes

\section{0}

$$
q=(1 / n) k_{a} D^{2}\left(k_{r} D\right)^{2 / 3} i^{1 / 2}
$$

Substituting for $D$ in terms of $\tau$ and $i$ from equation (4) and simplifying gives

। $q=(1 / n) k_{a} k_{r}^{-2}(\tau / \rho \mathrm{g})^{8 / 3} i^{-13 / 6}$

Writing $\tau$ as $\tau_{\min }$ in equation (11) and rearranging gives an expression for $i_{\text {min }}$, the minimum gradient for any particular wastewater flow rate

$$
i_{\min }=\left[(1 / n) k_{a} k_{r}^{-2}\right]^{6 / 13}\left(\tau_{\min } / \rho \mathrm{g}\right)^{16 / 13} q^{-6 / 13}
$$

Using the values of $\tau_{\min }$ and minimum proportional depth of flow employed for designing simplified sewerage in Brazil $\left(1 \mathrm{~N} / \mathrm{m}^{2}\right.$ and $0 \cdot 2$, respectively) yields

$$
i_{\min }=2 \cdot 33 \times 10^{-4} q^{-6 / 13}
$$

Rearranging equation (10) and inserting the value for $i_{\text {min }}$ given by equation (13) provides a means of calculating the minimum sewer diameter required to accommodate the maximum predicted peak flow, and also a means of determining the maximum size of sewer that will transport the minimum peak flow without either the proportional depth or the tractive tension falling below its specified minimum value

\section{4}

$$
D=(n q)^{3 / 8} k_{a}^{-3 / 8} k_{r}^{-1 / 4} i_{\min }^{-3 / 16}
$$

For example, for a minimum peak flow of $1.5 \mathrm{l} / \mathrm{s}$, either a $100 \mathrm{~mm}$ or a $150 \mathrm{~mm}$ dia. sewer may be used, but equation (14) shows that the maximum diameter that satisfies the design criteria is approximately $180 \mathrm{~mm}$.

\subsection{Development of a design template}

The design procedure consists of determining the minimum gradient $i_{\text {min }}$ using equation (14) and the initial (minimum) peak flow $q_{\mathrm{i}}$. Using the minimum gradient, the size of sewer required to convey the final (maximum) peak flow $q_{\mathrm{f}}$ is calculated using equation (14) at the maximum proportional depth of flow (0.8). If necessary, the next larger commercially available pipe size would be chosen. It is also necessary to check, for the initial flow, that the chosen sewer diameter does not exceed the maximum diameter for the minimum depth of flow using equation (14), or that the proportional depth of flow is less than the design minimum $(0 \cdot 2)$. 


\begin{tabular}{|lccc|}
\hline State & $\begin{array}{l}\text { Simplified sewerage cost: } \\
\text { US\$/household }\end{array}$ & $\begin{array}{l}\text { Conventional sewerage cost: } \\
\text { US\$/household }\end{array}$ & Notes \\
\hline Rio Grande do Norte & 350 & $\approx 1500$ & $1983 \operatorname{costs}^{5}$ \\
São Paulo & $440-790$ & $800-1550$ & $1988 \operatorname{costs}^{11}$ \\
Federal District & $170-340$ & $500-1500$ & $1997 \operatorname{costs}^{8}$ \\
Pará & 56 & 94 & $1997 \operatorname{costs}^{4}$ \\
\hline Table I. Capital costs of simplified and conventional sewerage in Brazil & & \\
\hline
\end{tabular}

While this procedure can be simplified to some extent by the use of tables (for example, a table of $k_{a}$ and $k_{r}$ for different proportional depths of flow ${ }^{12}$ ), it nevertheless remains a rather involved and time-consuming process. One alternative is to automate the design process using computers to calculate the required pipe sizes and gradients, ${ }^{13}$ but this approach will be constrained by the availability of computers and the necessary skilled engineers and technicians in developing countries. However, a design chart can be developed relatively simply with a standard spreadsheet program wherein all of the design conditions can be represented in a single diagram. ${ }^{14}$ The template in Figure 3 shows, for any flow, the minimum gradient permitted and, for one or more sewer diameters, the upper and lower limits of flow for any gradient. Figure 3 was constructed using the design values used for simplified sewerage design in Brazil given above and Manning's $n=0 \cdot 013$.

To construct the template, the independent variable was taken as the gradient and the following were calculated

(a) the minimum flow for the value of gradient selected using equation (11) with $\tau=1 \mathrm{~N} / \mathrm{m}^{2}$

(b) using equation (11), for each sewer size to be included in the template and for each value of gradient, the minimum flow using $k_{a}$ and $k_{r}$ for the minimum proportional depth of flow
$(0 \cdot 2)$, and the maximum flow using $k_{a}$ and $k_{r}$ for the maximum proportional depth of flow $(0 \cdot 8)$.

Further points in the development of the design template are as follows.

(c) When the rate of flow determined from equation (11) falls below the chosen value of $q_{\min }$, then this chosen value of $q_{\text {min }}$ (typically $1.5 \mathrm{l} / \mathrm{s}$ ) is used and a horizontal line on the graph is the result.

(d) For a $100 \mathrm{~mm}$ dia. sewer, the minimum gradient is governed by the minimum peak flow rather than by equation (13), since the minimum gradient that gives a proportional depth of flow of 0.2 at a flow of $1.5 \mathrm{l} / \mathrm{s}$ is about 1 in 9 and so is outside the range of the graph.

(e) Where more than two sewer diameters are to be included in one template, it may be more convenient to use a log scale for the flow axis.

\subsection{Using the design template}

To illustrate the use of the template, the following example will be used based on an initial peak flow rate $\left(q_{\mathrm{i}}\right)$ of $2 \mathrm{l} / \mathrm{s}$ and a final peak flow rate $\left(q_{\mathrm{f}}\right)$ of $4 \mathrm{l} / \mathrm{s}$ (which allows for future housing development or an increase in water consumption and hence wastewater generation).

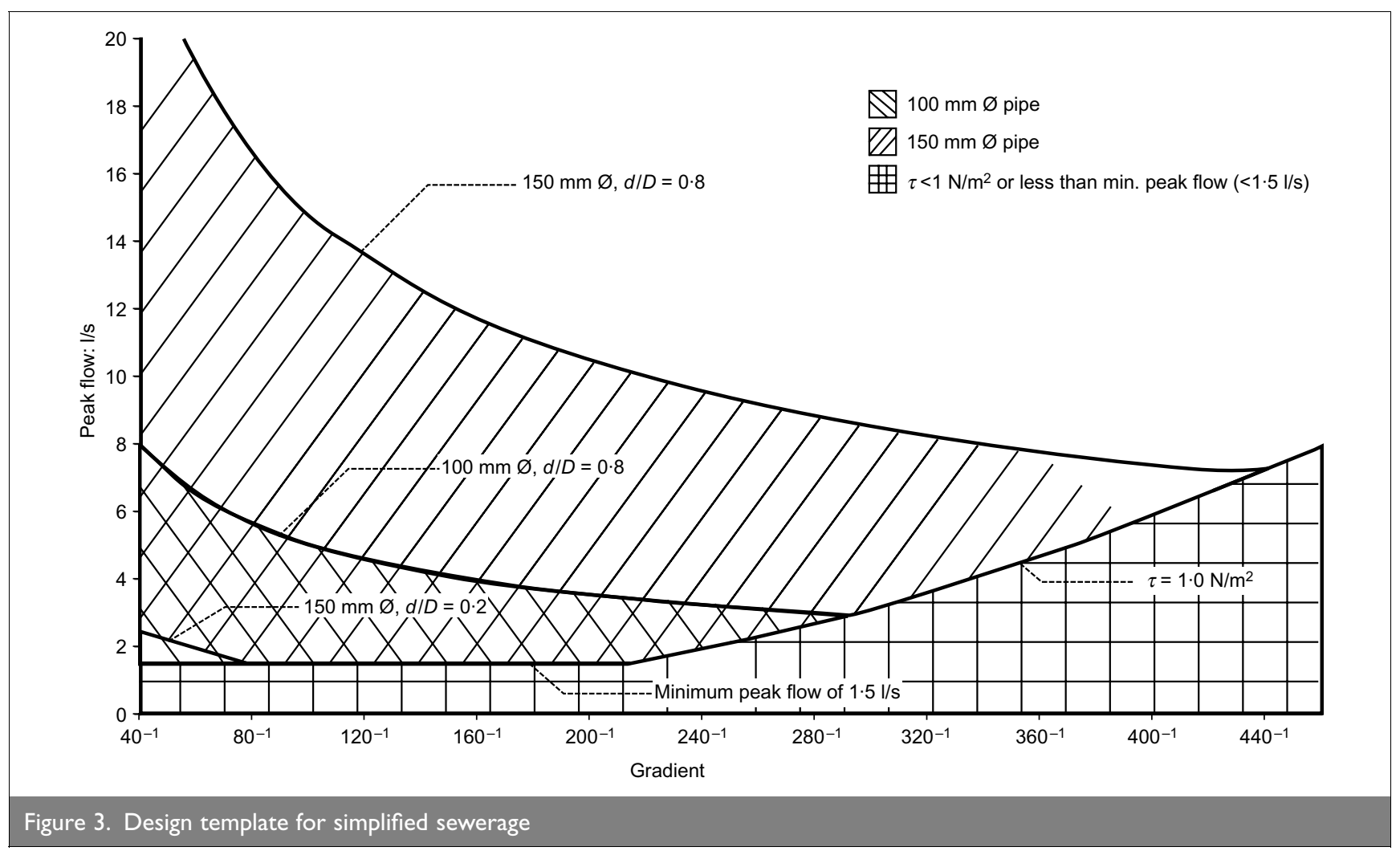




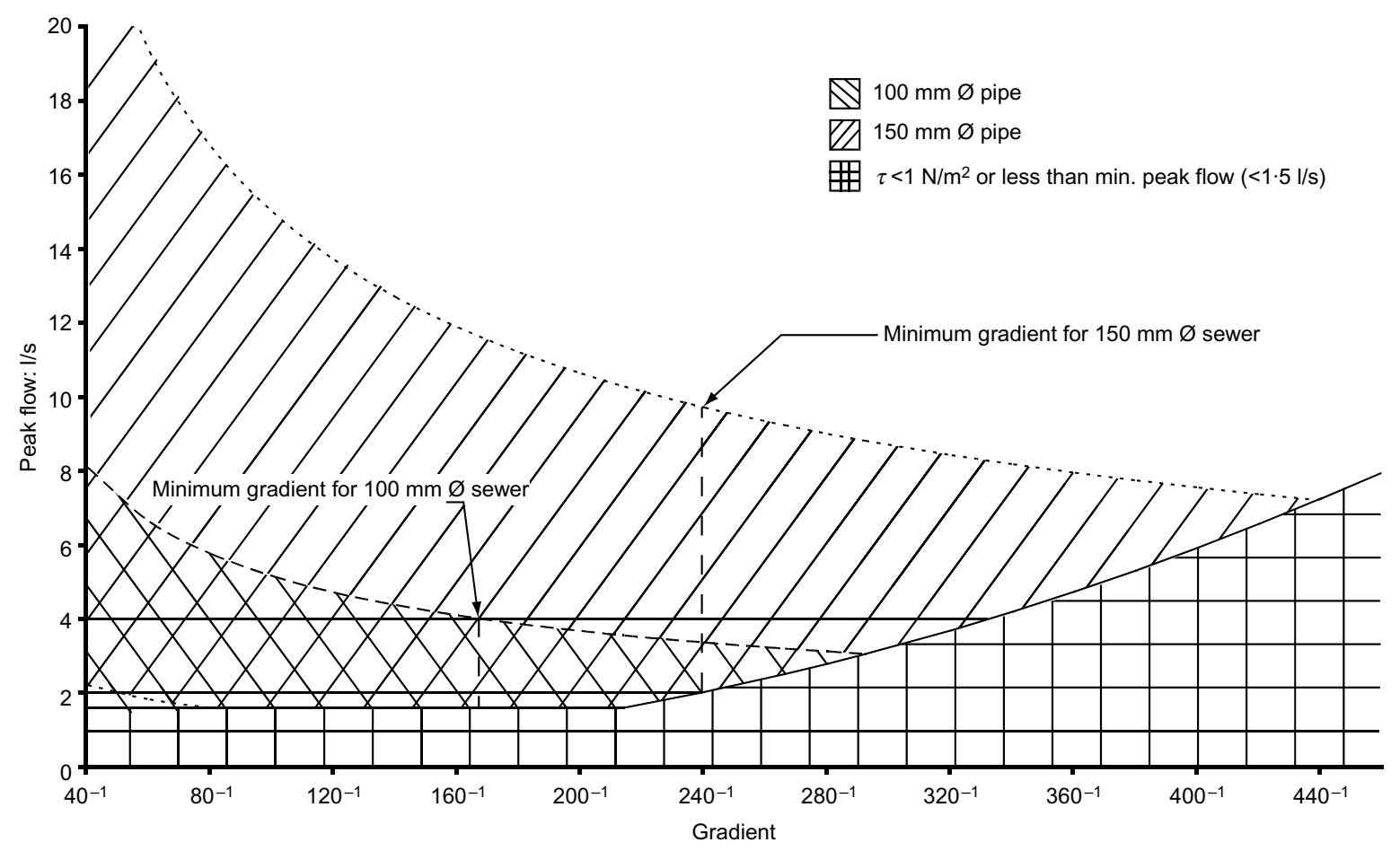

Figure 4. Design template for simplified sewerage example: initial peak flow of $21 / \mathrm{s}$ and final peak flow of $4 \mathrm{l} / \mathrm{s}$

From Figure 4, which is Figure 3 superimposed with lines for $2 \mathrm{l} / \mathrm{s}$ and $4 \mathrm{l} / \mathrm{s}$, it can be seen that the minimum gradient at the initial peak flow of $2 \mathrm{l} / \mathrm{s}$ is 1 in 240 . However, at this gradient, the maximum capacity of a $100 \mathrm{~mm}$ dia. sewer is approximately $3 \cdot 3 \mathrm{l} / \mathrm{s}$, which is less than the final peak flow of $4 \mathrm{l} / \mathrm{s}$. There are therefore two options: select either a larger sewer diameter or a steeper gradient. For the final peak flow of $4 \mathrm{l} / \mathrm{s}$, the maximum gradient for a $100 \mathrm{~mm}$ sewer is approximately 1 in 160 . If a $150 \mathrm{~mm}$ dia. sewer is chosen, it should be noted that this should not be laid at a gradient steeper than about 1 in 45 , otherwise the proportional depth of flow would fall below the design minimum of $0 \cdot 2$, although in practice this probably does not matter because the tractive tension at this gradient would be almost $4 \mathrm{~N} / \mathrm{m}^{2}$.

\section{SUPPORTING EVIDENCE FROM THE USA AND THE UK}

In Brazil, a review of a wide range of research and practice has led to the development of a consistent set of design rules based on setting values for six design parameters. In addition to fieldbased evidence that the long-term performance of simplified sewerage is generally extremely good, ${ }^{7}$ there is substantial evidence of the soundness of the basic assumptions from a number of other sources. For instance, in Nebraska there has been a long and successful history of using 'flat grade sewers', that is $150 \mathrm{~mm}$ and $200 \mathrm{~mm}$ dia. sewers laid at gradients as flat as 1 in 900, without any 'unusual' maintenance requirements. ${ }^{15}$

In the UK, existing sewer design practice is based on the concept of a 'self-cleansing velocity' to be achieved at the daily peak flow, but in recent years there has been an attempt to introduce elements of tractive tension design, although so far with only very limited success. The 1996 report Design of Sewers to Control Sediment Problems ${ }^{16}$ (Ciria report 141) outlined objectives that included reducing the cost of small-diameter sewers as these tend to be overdesigned when relying on a single value for the selfcleansing velocity, and reducing the maintenance requirements of large-diameter sewers where sediment accumulation is often problematic. A measure of the regrettable lack of impact of this initiative is that the 2006 edition of Sewers for Adoption ${ }^{17}$ (the code of practice for sewerage that governs the adoption of sewers by the statutory sewerage undertakers in England) does not mention Ciria report 141 at all, despite a number of English water companies being represented on the steering committee that guided the development of the report.

However, a comparison between Brazilian simplified sewerage design and Ciria report 141 shows that, for foul sewers of the size of interest (mainly 100 and $150 \mathrm{~mm}$ dia. sewers), very similar values for tractive tension are achieved by the two methods despite their differences in approach. Table 2 shows the values of tractive tension at the minimum flow condition for simplified sewerage calculated for 100, 150 and $225 \mathrm{~mm}$ dia. sewers using the recommended full-bore velocities and gradients given in Ciria report 141 for the erosion of sediment (assumption $C$ in Table $4 \cdot 5^{16}$ for $100 \mathrm{~mm}$ dia. pipes and Box 11 for 150 and $225 \mathrm{~mm}$ dia. pipes). These results show that for $150 \mathrm{~mm}$ dia. sewers the two methods are in close agreement. However, a lower gradient and tractive tension are given by the simplified sewerage method for $100 \mathrm{~mm}$ dia. sewers, and vice versa for $225 \mathrm{~mm}$ pipes.

Annex $C$ to the standard governing the design of drains and sewers in the UK (BS EN 752-4: 1998) ${ }^{18}$ contains a provision that is equivalent to the minimum flow criterion of simplified sewerage but which is not included in Sewers for Adoption, namely that the minimum flow should be taken as $1.6 \mathrm{l} / \mathrm{s}$ (i.e. close to the value of $1.5 \mathrm{l} / \mathrm{s}$ used in Brazil). Furthermore, a method for determining the design flow for small numbers of 
Ciria report 141

\begin{tabular}{|c|c|c|c|c|c|c|}
\hline \multicolumn{2}{|l|}{ Full bore } & \multicolumn{3}{|c|}{ Minimum flow } & \multicolumn{2}{|c|}{ Brazilian simplified sewerage } \\
\hline $\begin{array}{l}\text { Internal } \\
\text { diameter: } \mathrm{mm}\end{array}$ & Gradient & $q_{\min }: 1 / \mathrm{s}$ & $\begin{array}{l}\text { Proportional } \\
\text { depth of flow, d/D }\end{array}$ & $\tau: \mathrm{N} / \mathrm{m}^{2}$ & $\begin{array}{l}\text { Minimum } \\
\text { gradient }\end{array}$ & $\tau: \mathrm{N} / \mathrm{m}^{2}$ \\
\hline $\begin{array}{l}100 \\
150 \\
225\end{array}$ & $\begin{array}{l}143^{-1} \\
217^{-1} \\
317^{-1}\end{array}$ & $\begin{array}{l}1.5 \\
1.5 \\
2.5\end{array}$ & $\begin{array}{l}0.38 \\
0.24 \\
0.20\end{array}$ & $\begin{array}{l}1.40 \\
0.96 \\
0.84\end{array}$ & $\begin{array}{l}214^{-1} \\
214^{-1} \\
266^{-1}\end{array}$ & $\begin{array}{l}1.0 \\
1.0 \\
1.0\end{array}$ \\
\hline
\end{tabular}

Table 2. Comparison of Ciria report $|4|^{16}$ and Brazilian simplified sewerage

connections is also contained in this standard. If these provisions were to be used in practice for sewer design in the UK, there would then be little or no justification in continuing to use the extremely conservative limits on gradients that are included in Sewers for Adoption and also in the National Annex of BS EN 752-4: 1998.

The underlying principles of simplified sewerage are also reinforced by a study carried out on the blockage of sewers in the UK, which concluded that the two principal factors leading to sewer blockages were the level of hydraulic utilisation of the sewer (i.e. $d / D$ ) and standards of workmanship during sewer laying. ${ }^{19}$ In particular, there did not seem to be any strong relationship between sewer blockage and sewer gradient. In fact, in a survey of about 200 sewer lengths with no reported history of recurrent blockages, it was found that a higher proportion of sewers with gradients in the recommended range of 1 in 33 to 1 in 70 had experienced blockages than either those with steeper or shallower gradients; one short length of sewer was even found to be operating satisfactorily at a gradient of only 1 in 1200 .

Simplified sewerage explicitly addresses the level of hydraulic utilisation by its wide permissible range of proportional depth of flow $(0 \cdot 2-0 \cdot 8)$ and by selecting the smallest sewer diameter that will accommodate the anticipated maximum flow, so exemplifying the hydraulic dictum 'small flows flow better in small pipes'.

\section{CONSTRUCTION OF SIMPLIFIED SEWERAGE SYSTEMS}

Ensuring that a sewerage system is designed to function as hydraulically efficiently as possible obviously reduces its construction cost, but there are several other design aspects that significantly reduce costs even further. These include siting sewers in areas where there is little chance of damage from traffic loads, e.g. through back yards, front yards or in narrow lanes. ${ }^{5,11}$ In-block sewers have the advantages that they can be laid at shallow depths, typically with only $200 \mathrm{~mm}$ cover, and that two rows of houses can be served by a single sewer branch, so minimising the length of sewer per connection. Major cost savings can also be made through the use of plastic pipes as these are easy to produce to a high quality, are commonly available in $3 \mathrm{~m}$ lengths, and are easy to lay with simple and long-lasting joints. Concrete, asbestos cement and vitrified clay pipes can be used but they have a number of disadvantages including their greater weight, shorter lengths, more difficult means of jointing and, in the case of concrete and asbestos cement pipes, a greater likelihood of corrosion due to hydrogen sulfide internally and groundwater externally.
Substantial cost savings are achieved by using simple sewer appurtenances, such as the plastic junction box shown in Figure 5, rather than expensive manholes as required in conventional sewerage. A further disadvantage of manholes in many developing cities is that they are often poorly constructed with missing or broken covers, so that large quantities of grit and other debris enter the sewers. This is frequently compounded by solid waste being deliberately dumped into them and open stormwater drains being connected to sewers designed only for foul drainage. In such circumstances, the use of larger-thannecessary diameter sewers merely increases the capacity of the system to store solids before blocking completely. In fact, although it delays complete blockage, it also makes it more likely to occur and, when it does occur, much more difficult and costly to rectify due to the greatly increased quantity of solids to be removed. Unless manholes are constructed to a high standard (which is expensive) and any sewer blockages promptly cleared,

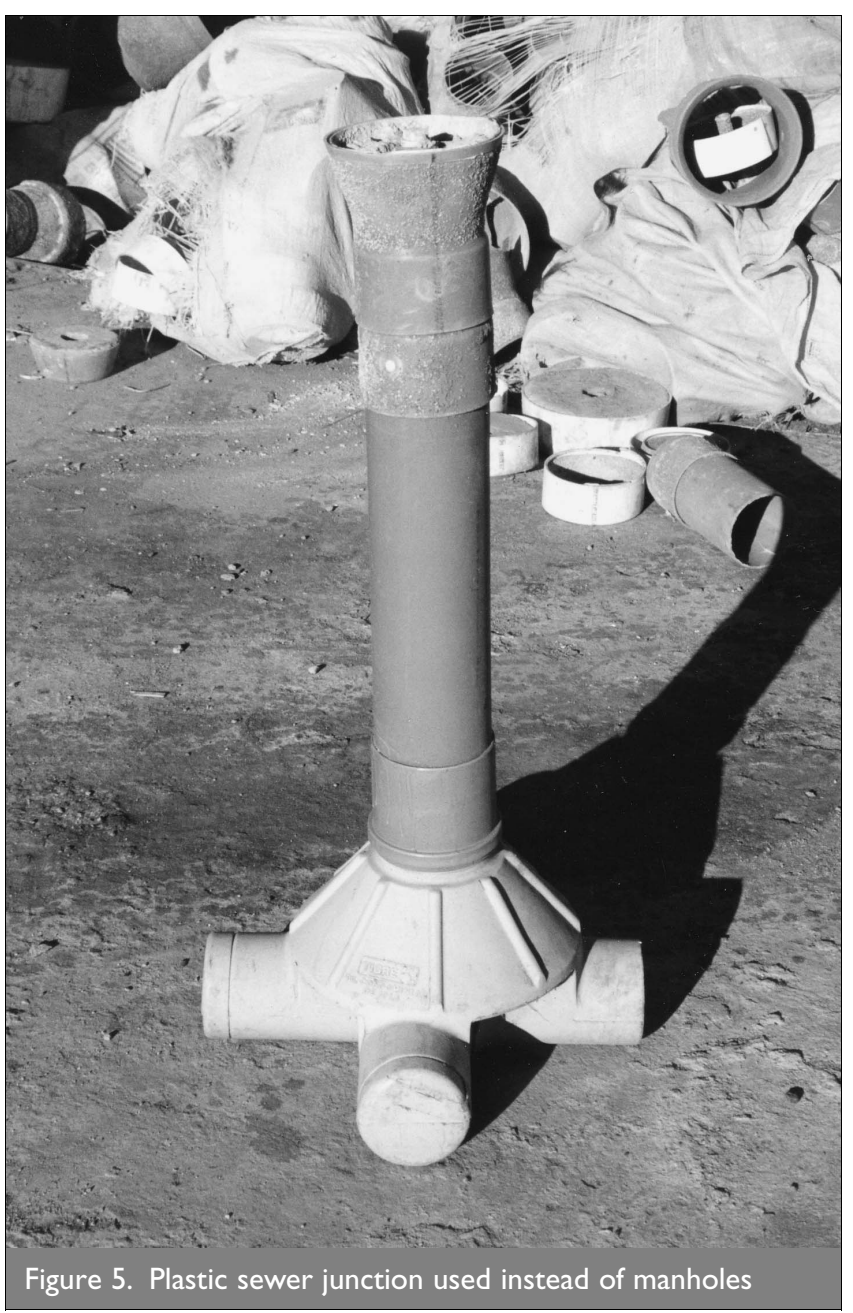


they are more likely to be part of the problem than part of the solution. This conclusion is reinforced by a study into sewer blockage in the UK ${ }^{19}$ where $19 \%$ of serious sewer defects were associated with manholes. (The only defect that was more common was associated with pipe jointing and, given the improvements in pipe materials and jointing since this study was carried out in the 1970s, it is likely that the proportion of manhole defects is now higher.)

\section{IMPEDIMENTS TO THE ADOPTION OF SIMPLIFIED SEWERAGE}

A number of projects using some or all of the elements of simplified sewerage have been reported as having a number of serious problems and some as being total failures. ${ }^{20}$ The reasons cited include technical failures, largely due to errors in design, materials used and standards of construction. However, failures often occur through factors external to the individual projects, such as the provision of downstream infrastructure (e.g. collector sewers by city or national bodies), pumping stations not operated as intended or failure to ensure adequate provision for future maintenance.

Such is the recognition of the importance of maintaining high construction standards in Brazil, many state water and sewerage companies ensure the hydraulic integrity of their simplified sewers by allowing the sewers to be laid only by contractors they have trained to lay a $100 \mathrm{~mm}$ sewer at a gradient of 1 in 200 to a rigorous standard. However, the examples of failed projects seem to indicate that trying to adapt existing standards and practices to provide sewerage at lower cost is unlikely to be very successful. For instance, 'haudis', or small interceptor tanks, have been used in a number of projects in Asia. ${ }^{21}$ While these may reduce the amount of silt entering sewers, they have the disadvantage of reducing the peak flow from individual connections and so reducing the capacity of the sewer to transport sediment; they also increase the responsibility for maintenance by individual households without any certainty that it will be carried out. In Brazil, some connections (such as those from commercial establishments where there is perceived to be a high risk of large objects entering the sewer) are provided with 'baffled boxes', but they are designed to avoid sedimentation and are not usually installed on domestic connections. ${ }^{6,11}$ It should also be noted that the use of concrete or asbestos cement pipes is not recommended for simplified sewerage due to the high probability of sulphide attack on the pipe material. ${ }^{13}$

It is clear that projects are unlikely to succeed without full agreement with and commitment to technical standards and the social and institutional arrangements for future management and maintenance of the system by all parties affected. ${ }^{22}$ It is a mistake, however, to assume that this is too difficult to achieve for a simplified sewerage scheme and that on-site solutions should be pursued instead. Even for the simplest sanitation technologies, all factors (technical, economic/financial, social and institutional) have to be taken into account; however, the removal, transport and disposal of faecal sludge from on-site systems are serious problems for which, at present, there are no simple solutions.

It seems that many sewerage design engineers are unable or unwilling to accept that there are alternatives to traditional, conservative approaches to sewer design, or that substantial cost savings can be made without an intolerable increase in maintenance requirements. Traditional methods are usually based on the concept of a self-cleansing velocity but also include numerous other restrictions, such as a larger-than-necessary minimum sewer diameter and a limit on the number of connections that can be served by a sewer of any given size. These lack any theoretical or empirical basis and may also have unintended but potentially serious consequences.

In most parts of Africa and Asia, there is a fundamental lack of understanding of the principles of simplified sewerage design and construction. Should there be adequate evidence from actual practice to justify a revision of the design rules, care should be taken to ensure that any changes do not conflict with the consistency and simplicity of the design method. For instance, if it seems that there is likely to be an unacceptable increase in sewer blockages, then the answer should be to increase the design value for minimum tractive tension, rather than to import outdated empirical rules from conventional sewerage.

\section{CONCLUDING REMARKS}

Simplified sewerage has the potential to provide a high-quality low-cost sanitation service in poor urban areas throughout the developing world. However, its hydraulic design principles need to be properly understood and applied correctly if this potential is to be realised. Given that simplified sewerage is likely to be the principal way by which the UN millennium development goals sanitation target can be met in high-density urban areas, there is a pressing need for this sanitation system, together with its hydraulic intricacies, to be disseminated widely throughout the developing world. This is an activity that should exercise the minds not only of senior engineers and planners in ministries of water, local government and finance in developing countries, but also of senior policy makers in multinational and bilateral aid agencies. Unfortunately, at the present time, there is little evidence of this happening-to the detriment and death of the urban poor.

\section{REFERENCES}

1. World Health Organization/Unicef. Global Water Supply and Sanitation Assessment Report 2000. WHO, Geneva, 2000.

2. World Health Organization/Unicef. Meeting the MDG Drinking Water and Sanitation Target: The Urban and Rural Challenge of the Decade. WHO, Geneva, 2006.

3. DE Andrade Neto C. O. Uma solução eficaz e de baixo custo para o esgotamento sanitário urbano. Engenharia Sanitária, 1985, 24, No. 2, 239-241.

4. Melo J. C. The Experience of Condominial Water and Sewerage Systems in Brazil: Case Studies from Brasília, Salvador and Parauapebas. Water and Sanitation Program Latin America, Lima, 2005.

5. Sinnatamby G. S. The Design of Shallow Sewer Systems. United Nations Centre for Human Settlements, Nairobi, 1986.

6. Associação Brasileira de Normas Técnicas. Projeto de Redes Coletoras de Esgoto Sanitário. ABNT, Rio de Janeiro, 1986.

7. SARMento V. De B. A. Low-cost Sanitation Improvements in Poor Communities: Conditions for Physical Sustainability. PhD thesis, University of Leeds, 2001.

8. Neder K. D. and Nazareth P. Condominial Sewer Systems for the Federal District of Brazil, Part 3: Methodology for the 
Application of Condominial Sewer Systems in the Federal District of Brazil. Companhia de Saneamento Ambiental do Distrito Federal, Brasília, 1998.

9. See http://duncanmarasanitation.blogspot.com/2008/01/ simplifiedcondominial-sewerage- $2 . \mathrm{html}$.

10. Machado Neto J. C. 0. and TsutiYa M. T. Tensão trativa: um critério econômico de esgoto. Revista DAE, 1985, 45, No. 140, 73-87.

11. Bakalian A., Wright A., Otis R. and Azevedo-Netto J. Simplified Sewerage: Design Guidelines. World Bank, Washington, DC, 1994.

12. Mara D. Simplified sewerage: simplified design. In Lowcost Sewerage (Mara D., (ed.)). Wiley, Chichester, 1996, pp. 169-174.

13. Mara D. D., Sleigh P. A. and Tayler K. PC-based Simplified Sewerage Design. School of Civil Engineering, University of Leeds, 2001.

14. Broome J. A simple aid for designing sewers. Journal of the Chartered Institution of Water and Environmental Engineering, 1996, 10, No. 6, 411-412.

15. Gidley J. S. Ericson, Nebraska Flat Grade Sewers. National Small Flows Clearinghouse, West Virginia University, Morgantown, 1987, Case Study No. 11.
16. Ackers J. C., Butler D. and May R. W. P. Design of Sewers to Control Sediment Problems. Construction Industry Research and Information Association, London, 1996, Report No. 141.

17. Water Research Centre. Sewers for Adoption: A Design and Construction Guide for Developers, 6th edn. WRc, Swindon, 2006.

18. British Standards Institution. Drains and Sewer Systems Outside Buildings-Part 4: Hydraulic Design and Environmental Considerations. BSI, London, 2005, BS EN 752-4: 1998.

19. LILlywhite M. S. T. and WebsteR C. J. D. Investigations of drain blockages and their implications on design. Journal of the Institution of Public Health Engineers, 1979, 7, No. 4, 170-175.

20. TAYLER K. Urban sanitation-lessons from experience. Waterlines, 2008, 27, No. 1, 30-47.

21. Khatib Alam S. M. and Parkinson J. Appropriate Design Standards and Construction Specifications for Tertiary Sewerage Systems. Faisalabad Area Upgrading Project, Faisalabad, 2002.

22. Watson G. Good Sewers Cheap? Agency-Customer Interactions in Low-cost Urban Sanitation in Brazil. World Bank, Washington, DC, 1995.

\section{What do you think?}

To comment on this paper, please email up to 500 words to the editor at journals@ice.org.uk

Proceedings journals rely entirely on contributions sent in by civil engineers and related professionals, academics and students. Papers should be 2000-5000 words long, with adequate illustrations and references. Please visit www.thomastelford.com/journals for author guidelines and further details. 